\title{
Efficiency of Iron Supported on Porous Material (Prepared from Peanut Shell) for Liquid Phase Aerobic Oxidation of Alcohols
}

\author{
Mohammad Sadiq, Razia, Sajid Hussain, Gul Zamin \\ Department of Chemistry, University of Malakand, Chakdara, Pakistan \\ Email: sadiq@uom.edu.pk, mohammad sadiq26@yahoo.com
}

Received 24 January 2014; revised 24 February 2014; accepted 1 March 2014

Copyright (C) 2014 by authors and Scientific Research Publishing Inc.

This work is licensed under the Creative Commons Attribution International License (CC BY).

http://creativecommons.org/licenses/by/4.0/

c) (i) Open Access

\section{Abstract}

Catalytic activity and selectivity of prepared catalysts $\left(\mathrm{Fe}_{2} \mathrm{O}_{3} / \mathrm{AC}_{\left(\mathrm{H}_{3} \mathrm{PO}_{4}\right)}\right.$ and $\left.\mathrm{Fe}_{2} \mathrm{O}_{3} / \mathrm{AC}_{(\mathrm{KOH})}\right)$ were investigated for liquid phase aerobic oxidation of primary and secondary alcohols, in a batch reactor, using solvent free condition and/or eco-friendly solvents. The catalysts were characterized by SEM, EDX, XRD, FTIR, TGA/DTA, and surface area and pore size analysis. Experimental data revealed that $\mathrm{Fe}_{2} \mathrm{O}_{3} / \mathrm{AC}_{(\mathrm{Kон)})}$ was an efficient catalyst for the oxidation (dehydrogenation) of alcohol while $\mathrm{Fe}_{2} \mathrm{O}_{3} / \mathrm{AC}_{\left(\mathrm{H}_{3} \mathrm{PO}_{4}\right)}$ was found to show catalytic activity for both dehydration and dehydrogenation of alcohols. The catalysts were recycled by simple filtration, and used several times without any loss of catalytic activity.

\section{Keywords}

Oxidation; Iron Oxide; Activated Carbon; Alcohol; Liquid Phase

\section{Introduction}

Alcohols can be oxidized to aldehydes and ketones in the presence of oxidizing agents, such as potassium dichromate added to sulphuric acid, chromic oxide added to glacial acetic acid, potassium permanganate, and sodium hypochlorite (bleach), etc. Primary alcohols are oxidized to aldehydes and secondary alcohols to ketones, while tertiary alcohols resist oxidation due to a lack of $\alpha$-hydrogen [1] [2]. In the last few years, researchers have focused on the replacement of these stoichiometric oxidants by oxygen in catalytic organic oxidation reactions [3]-[5]. In fact, using molecular oxygen as oxidant for the oxidation of alcohol has a practical impact on both economy and environment. The most important factor in the liquid phase oxidation of alcohol is solvent. In or- 
ganic solvent, reactions proceed efficiently but associated with it are problems such as inflammability, toxicity, and the difficulty of product separation [6] [7]. Due to these problems, we have switched over to the liquid phase oxidation in eco-friendly solvents or in solvent free conditions [8]-[10]. The selection of catalyst is a key to green and sustainable catalysis. Liquid phase oxidation of alcohol has been successfully performed using precious metals and supported precious metals which are both quite costly [11] [12]. To address all these problems, iron supported on activated carbon was experimented for the oxidation of alcohol without using any organic solvent.

\section{Experimental}

\subsection{General}

Chemicals used in the research were AR-grade. $\mathrm{H}_{2}$ (99.999\%) was prepared by hydrogen generator (GCD-300, BAIF). Nitrogen and Oxygen were supplied by BOC Pakistan, and were further purified by passing through filters (C.R.S.Inc. 202268), to remove traces of water and oil. Traces of oxygen from nitrogen gas were removed by using specific oxygen traps (C.R.S.Inc. 202223).

\subsection{Preparation of Activated Carbon}

1) Peanut shells were washed, dried, ground and mixed with 10 weight $\% \mathrm{KOH}$ solutions, in a ratio 6:100. The sample was sonicated for $10 \mathrm{~min}$ at $30^{\circ} \mathrm{C}$, and then shaked for 6 hours at $50^{\circ} \mathrm{C}$. After impregnation, the sample was immediately filtered, followed by washing with hot double distilled water, and subsequently dried.

2) In case of phosphoric acid activation, the ground peanut shells were mixed with 50 weight $\% \mathrm{H}_{3} \mathrm{PO}_{4}$ solution in 1:1 ratio, and allowed to soak in for 24 hours at room temperature. The impregnated samples as mentioned above were then charged into a quartz reactor and heated in tube furnace at $170^{\circ} \mathrm{C}\left( \pm 5^{\circ} \mathrm{C}\right)$ for one hour under a flow of nitrogen $(40 \mathrm{~mL} / \mathrm{min})$. The temperature was then increased to $450^{\circ} \mathrm{C}\left( \pm 5^{\circ} \mathrm{C}\right)$ in the same atmosphere and maintained for 1 hour. This was followed by cooling down the sample to room temperature under nitrogen flow. The cooled sample was washed in modified Soxhlet's apparatus, dried and sieved through US standard sieve (100 mesh).

\subsection{Preparation of Iron/Activated Carbon}

(w/w 10\%) Iron/activated carbon catalyst was prepared by standard incipient wetness technique. Calculated amount (4.32 g) of the precursor compound (Iron nitrate) was taken in a crucible, and sufficient amount of triple distilled water added to it. Then the required amount $(9 \mathrm{~g})$ of the support (activated carbon) was mixed with it. The paste was thoroughly homogenized and dried in an oven at $110^{\circ} \mathrm{C}$ for 24 hours and then ground. The ground catalyst was calcined at $350^{\circ} \mathrm{C}$ for 4 hours in inert atmosphere.

\subsection{Characterization of Catalyst}

Activated carbon and Iron/activated carbon catalysts were characterized by SEM/EDX (JSM 5910, JEOL, Japan), XRD (X-ray differactometer Rigaku D/Max-II, Cu tube, Japan), FTIR (Prestige 21 Shimadzu Japan in the range $500-4000 \mathrm{~cm}^{-1}$ ), Surface area and pore size analyzer (Quantachrome (Nova 2200e, USA) and TGA/DTA (Diamond Series PerkinElmer, USA).

\subsection{Catalytic Test}

Double walled three-necked batch reactor was charged with $10 \mathrm{ml}$ alcohol and $100 \mathrm{mg}$ catalyst. The reaction was performed for $1-8$ hours at $70^{\circ} \mathrm{C}-100^{\circ} \mathrm{C}$ with continuous stirring. Molecular oxygen was continuously bubbled through the reaction mixture. The rate of flow was kept at $40 \mathrm{~mL} / \mathrm{min}$. The reaction mixture (cyclohexanol/cyclohexanone system) was analyzed by chemical method using 2, 4-dinitrophenyl hydrazine. The reaction mixture was frequently analyzed by UV spectrophotometer, and GC equipped with FID. Products from the reaction carried out in the aqueous medium was extracted with ethyl acetate, and then analyzed by GC.

\section{Results and Discussion}

This research was carried out to study the efficiency of iron supported on porous material (prepared from peanut 
shell) for the liquid phase aerobic oxidation of alcohol. The morphology and surface characteristics were investigated through a variety of modern techniques. The catalyst was tested through a model reaction; liquid phase oxidation of cyclohexanol to cyclohexanone without any solvent under the following conditions:

Temperature range (343 to $373 \mathrm{~K}$ )

$\mathrm{N}_{2}$ flow $(40 \mathrm{~mL} / \mathrm{min})$ or $\mathrm{O}_{2}$ flow $(40 \mathrm{~mL} / \mathrm{min})$

Partial pressure of oxygen (95 Torr to 760 Torr)

Various volumes of reactant ( $3 \mathrm{~mL}$ to $18 \mathrm{~mL}$ )

Different catalyst loading ( $0.03 \mathrm{~g}$ to $0.3 \mathrm{~g})$

Different reaction durations (30 min to $480 \mathrm{~min}$ )

All these reaction parameters affect the rate of reaction and hence the effect of these is discussed in detail under a separate heading. The reaction mixture was frequently analyzed by chemical method, and by GC using FID.

\subsection{Catalyst Characterization}

Surface characterization in term of surface area and pore volume is given in Table $1 . \mathrm{AC}_{(\mathrm{KOH})}$ has lower $\mathrm{BET}$ surface area $\left(1126.37 \mathrm{~m}^{2} / \mathrm{g}\right)$ and pore volume $(0.81 \mathrm{cc} / \mathrm{g})$ than that of $\mathrm{AC}_{\left(\mathrm{H}_{3} \mathrm{PO}_{4}\right)}$ which has larger surface area $\left(1242.59 \mathrm{~m}^{2} / \mathrm{g}\right)$ and pore volume $(0.87 \mathrm{cc} / \mathrm{g})$. The increase in the BET surface area and pore volume of $\mathrm{AC}_{\left(\mathrm{H}_{3} \mathrm{PO}_{4}\right)}$ has brought about by oxidants, may be due to the opening of the pores. It was found that the physical morphology of the activated carbon is also affected by the strength of the oxidizing agent. The impregnation of iron on activated carbon reduces both surface area and pore volume, which may be due to the blocking of pores on the surface of activated carbon by iron as shown in Table 1.

FTIR spectra as shown in Figure 1 reveal the surface functional groups of activated carbon used as a support for the catalyst. Spectral peaks between $3100-3500 \mathrm{~cm}^{-1}$ (O-H, N-H stretching), $3000-3100 \mathrm{~cm}^{-1}$ (C-H aromatic), $2800-3000 \mathrm{~cm}^{-1}$ (C-H aliphatic), $1640-1750 \mathrm{~cm}^{-1}$ (C=O and C-O) can be attributed to phenolic ester, carboxylic acid, and conjugated ketonic structures. Bands appearing in the $1070-1080 \mathrm{~cm}^{-1}$ range may be ascribed to phosphorus and phosphor carbonaceous compounds. FTIR spectrum of $\mathrm{AC}_{(\mathrm{KOH})}$ and $\mathrm{AC}_{\left(\mathrm{H}_{3} \mathrm{PO}_{4}\right)}$ were compared and it was observed that the $\mathrm{AC}_{\left(\mathrm{H}_{3} \mathrm{PO}_{4}\right)_{1}}$ has intense band for carboxylic group, in comparison to $\mathrm{AC}_{(\mathrm{KOH})}$. The FT-IR peaks at $470 \mathrm{~cm}^{-1}$ and $570 \mathrm{~cm}^{-1}$ indicate the presence of hematite particles on surface of activated carbon, as shown in Figure 2.

SEM images of activated carbon impregnated with phosphoric acid show pores which are apparently more open as compared to that in $\mathrm{AC}_{(\mathrm{KOH})}$, as shown in Figures 3 and 4 . The results are in good agreement with that of BET surface area and pores size measurements as given in the Table 1.

EDX results (Figures 5 and 6) confirm the chemical composition of activated carbon; it comprises mainly carbon and oxygen. Besides, remains of impregnating reagents, i.e., $\mathrm{KOH}$ and $\mathrm{H}_{3} \mathrm{PO}_{4}$, are also observable in the elemental analysis [13]. Iron impregnated sample has Fe on the surface of activated carbon, a rough estimate of the content of which can be obtained from the EDX analysis.

Figures 7(a), (b) and 8(a), (b) represents the XRD patterns of the activated carbon and Iron oxide supported activated carbon. The XRD pattern of activated carbon presents with peaks at $2 \theta=24^{\circ}$ and $2 \theta=45^{\circ}$ which can be ascribed to amorphous morphology of the samples. Similar results have been previously reported that the activated carbons prepared from agricultural wastes are amorphous [13]. XRD pattern of iron oxide supported on activated carbon have peaks responsible for hematite and magnetite, appearing at $2 \theta=53.14^{\circ}$ and $2 \theta=69.8^{\circ}$.

Table 1. Surface characterization of activated carbon and Iron/Activated carbon, used as catalysts for the oxidation of alcohols in solvent free conditions and/or eco-friendly solvents.

\begin{tabular}{ccc}
\hline Catalyst & (BET) Surface area $\left(\mathrm{m}^{2} / \mathrm{g}\right)$ & $(\mathrm{BJH})$ Pore volume $(\mathrm{cc} / \mathrm{g})$ \\
\hline $\mathrm{AC}_{(\mathrm{KOH})}$ & 1126.37 & 0.81 \\
$\mathrm{Fe}_{2} \mathrm{O}_{3} / \mathrm{AC}_{(\mathrm{KOH})}$ & 1067.68 & 0.41 \\
$\mathrm{AC}_{\left(\mathrm{H}_{3} \mathrm{PO}_{4}\right)}$ & 1242.59 & 0.87 \\
$\mathrm{Fe}_{2} \mathrm{O}_{3} / \mathrm{AC}_{\left(\mathrm{H}_{3} \mathrm{PO}_{4}\right)}$ & 1232.98 & 0.80 \\
\hline
\end{tabular}




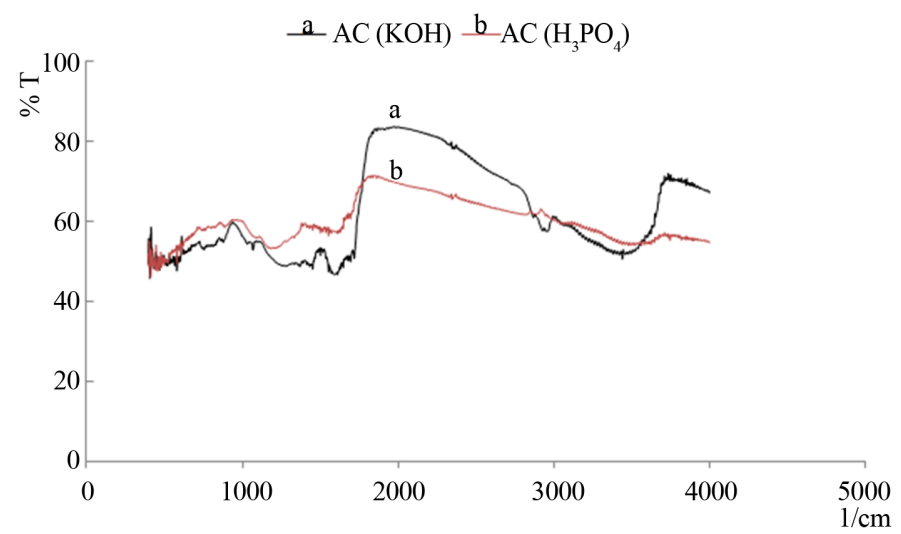

Figure 1. FTIR spectra of activated carbon treated with a. KOH and b. $\mathrm{H}_{3} \mathrm{PO}_{4}$.

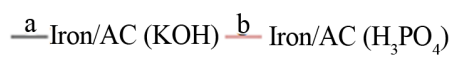

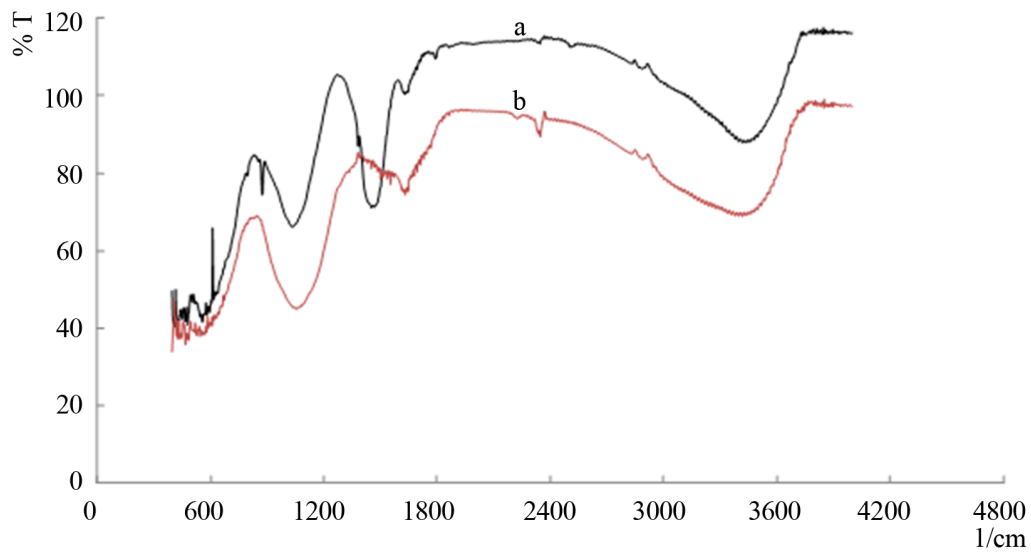

Figure 2. FTIR spectra of iron supported on activated carbon impregnated with a. $\mathrm{KOH}$ and b. $\mathrm{H}_{3} \mathrm{PO}_{4}$.
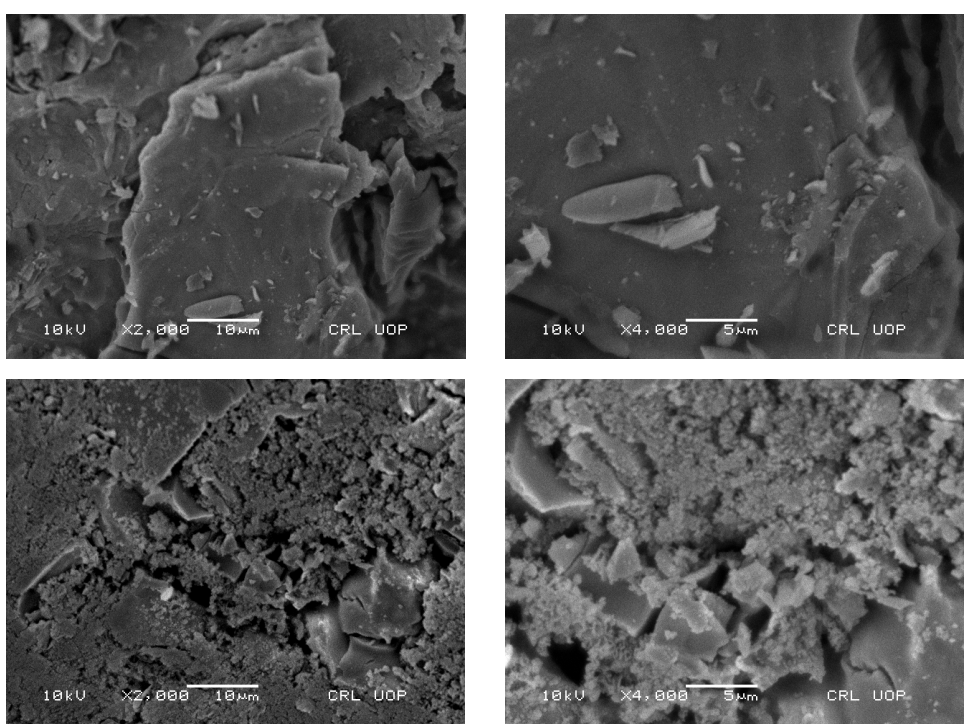

Figure 3. SEM images of activated carbon, and iron supported on activated carbon impregnated with $\mathrm{KOH}$ (magnification 2000 and 4000). 

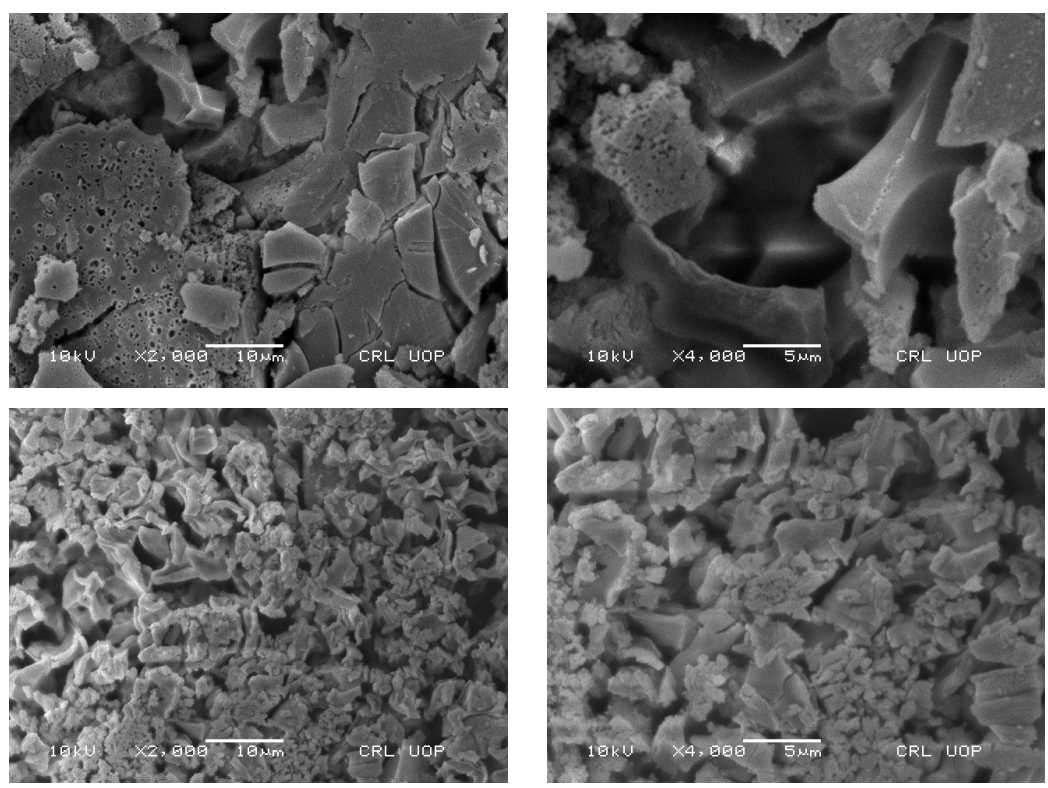

Figure 4. SEM images of activated carbon, and iron supported on activated carbon impregnated with $\mathrm{H}_{3} \mathrm{PO}_{4}$ (magnification 2000 and 4000).
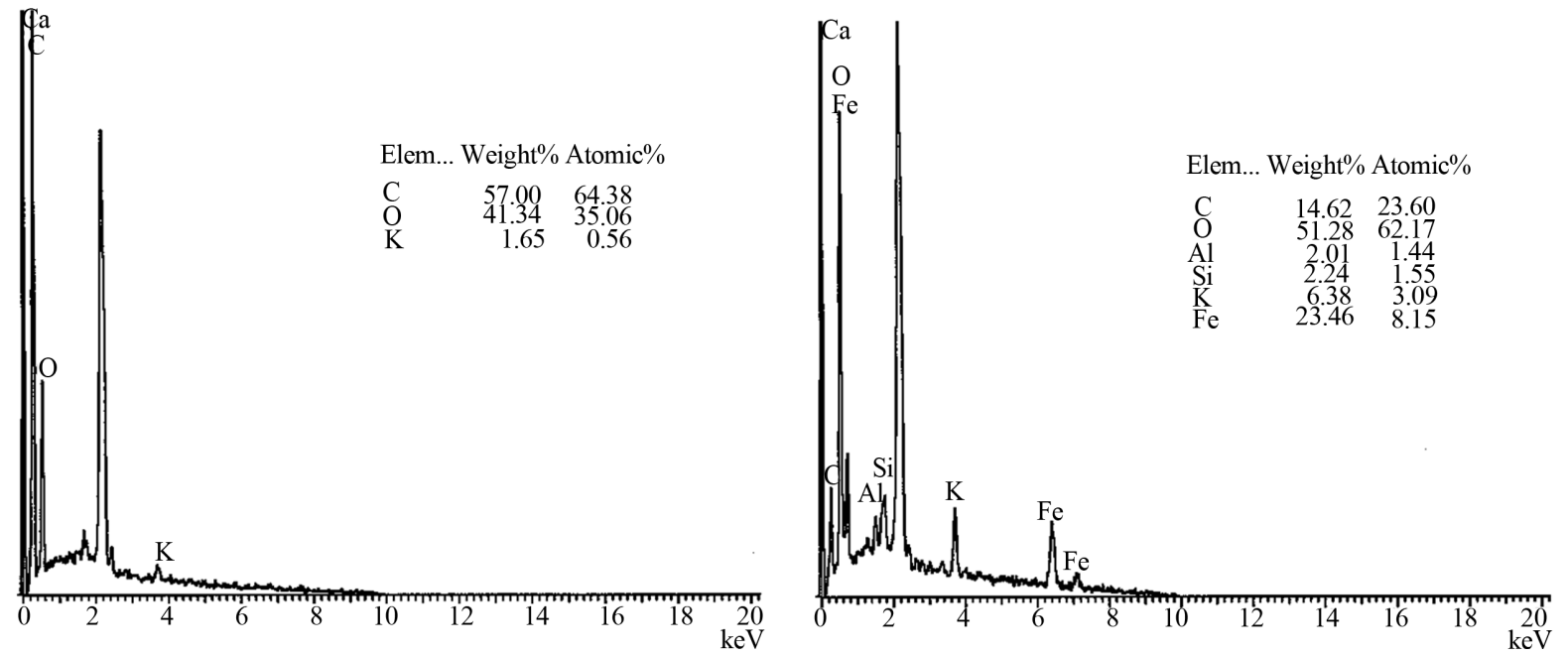

Figure 5. EDX of activated carbon, and iron supported on activated carbon treated with $\mathrm{KOH}$.

Figures 9(a), (b) and 10(a), (b) show TGA/DTA of activated carbon and iron oxide supported on activated carbon. The inspection of TGA/DTA of activated carbon reveals that the weight loss in the range $25^{\circ} \mathrm{C}-120^{\circ} \mathrm{C}$ occurs due to dehydration. In between $120^{\circ} \mathrm{C}-380^{\circ} \mathrm{C}$, catalyst is thermally stable and only a little weight loss occurs due to loss of volatile matter, while after $380^{\circ} \mathrm{C}$, a major weight loss occurs, which is commonly due to the oxidation of carbon. However, in case of iron impregnated sample the weight loss suddenly cessates at a lower temperature which is due to the presence of nitrate-acetate ions on the sample which bring about autocatalytic anionic oxidation-reduction reaction on the catalyst/carbon surface.

\subsection{Preliminary Studies with $\left(\mathrm{Fe}_{2} \mathrm{O}_{3} / \mathrm{AC}_{\left(\mathrm{H}_{3} \mathrm{PO}_{4}\right)}\right)$ and $\left(\mathrm{Fe}_{2} \mathrm{O}_{3} / \mathrm{AC}_{(\mathrm{KOH})}\right)$ Catalysts}

Two types of catalysts $\left(\mathrm{Fe}_{2} \mathrm{O}_{3} / \mathrm{AC}_{\left(\mathrm{H}_{3} \mathrm{PO}_{4}\right)}\right)$ and $\left(\mathrm{Fe}_{2} \mathrm{O}_{3} / \mathrm{AC}_{(\mathrm{KOH})}\right)$ were used for the liquid phase oxidation of cyclohexanol, under atmospheric pressure, using oxygen and/or nitrogen. These investigations were carried out by loading $100 \mathrm{mg}$ of catalyst in $10 \mathrm{~mL}$ of cyclohexanol to a three-necked batch reactor at 475 Torr of oxygen or 760 Torr of nitrogen, at a flow rate of $40 \mathrm{~mL} / \mathrm{min}$, with stirring at $900 \mathrm{rpm}$, for 8 hours at a temperature of $363 \mathrm{~K}$. 

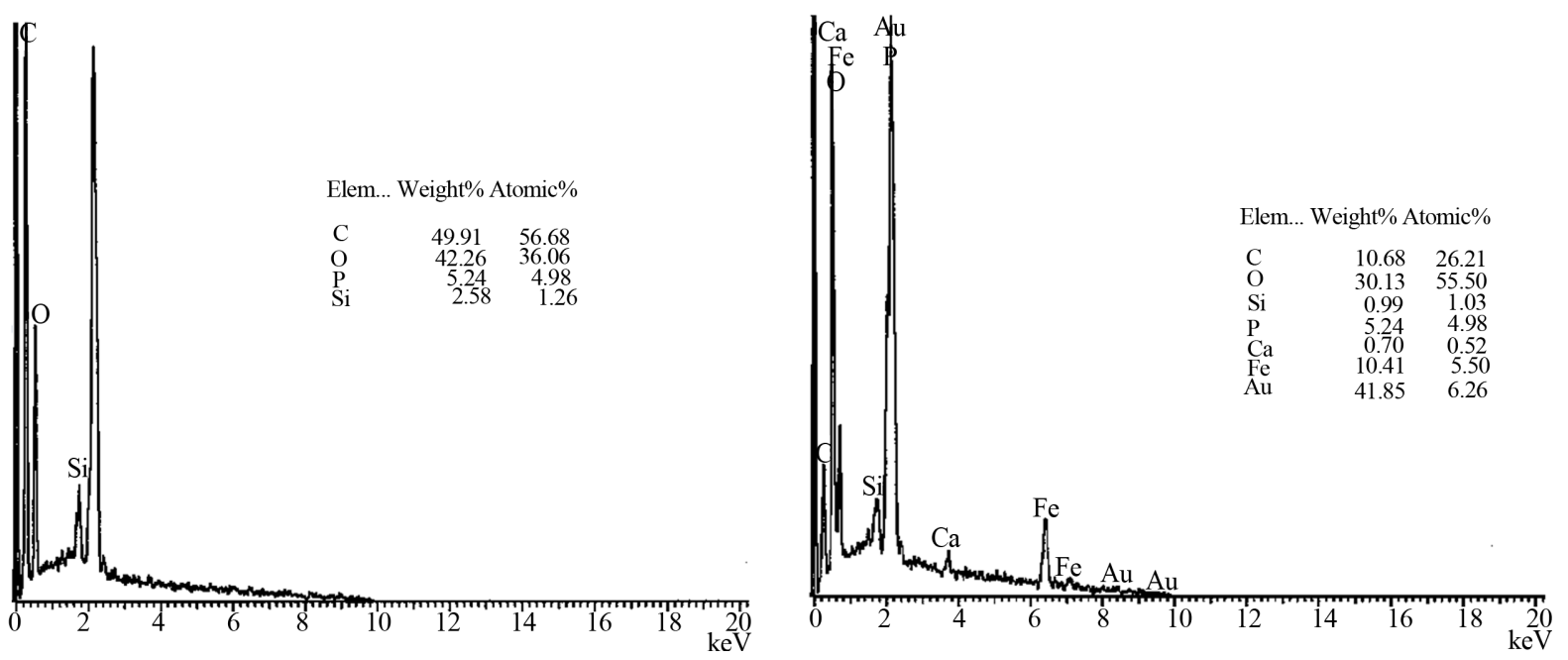

Figure 6. EDX of activated carbon, and iron supported on activated carbon treated with $\mathrm{H}_{3} \mathrm{PO}_{4}$.

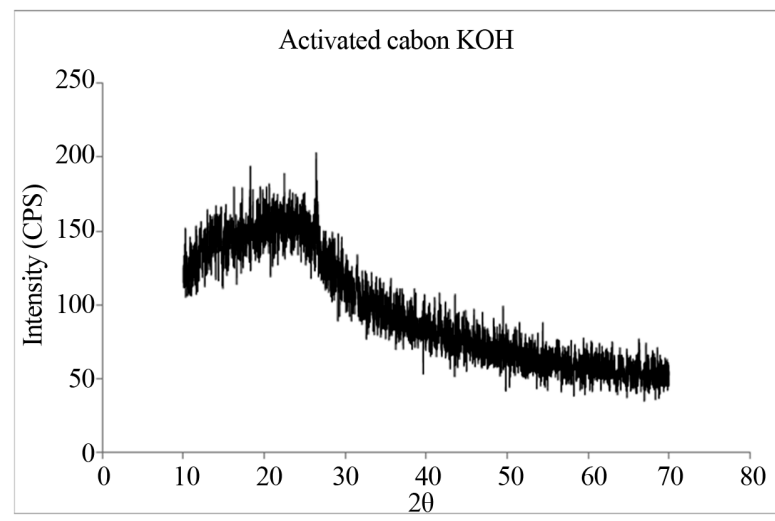

(a)

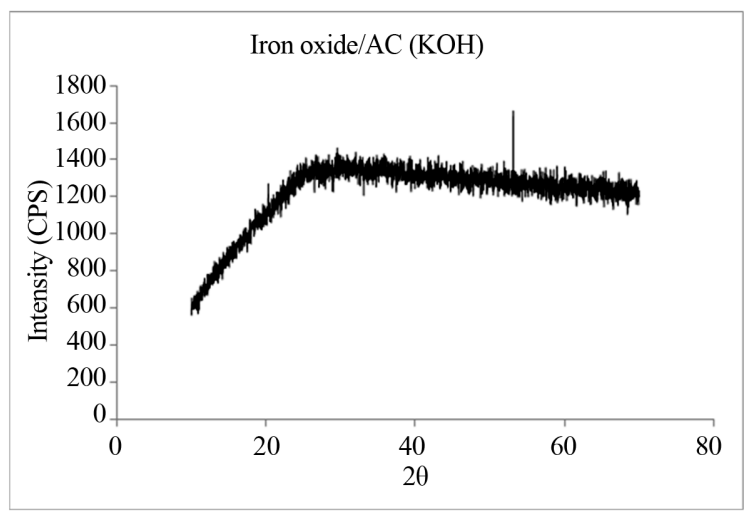

(b)

Figure 7. (a) XRD of activated carbon impregnated with KOH; (b) XRD of iron supported on activated carbon impregnated with $\mathrm{KOH}$.

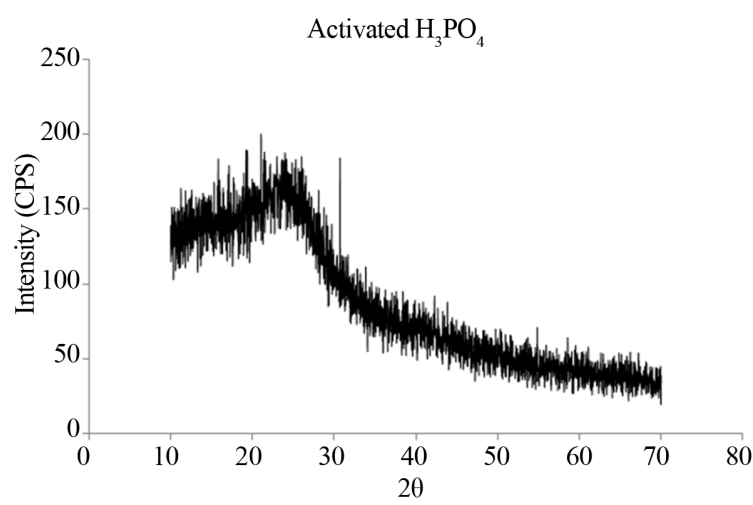

(a)

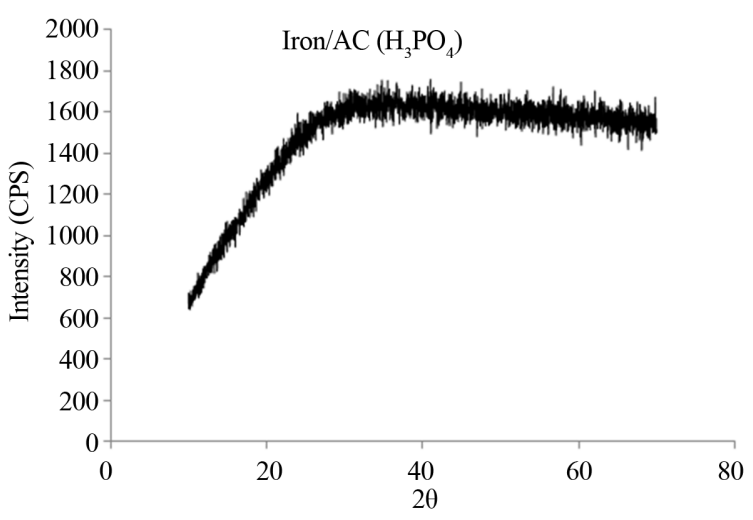

(b)

Figure 8. (a) XRD of activated carbon impregnated with $\mathrm{H}_{3} \mathrm{PO}_{4}$; (b) XRD of iron supported on activated carbon impregnated with $\mathrm{H}_{3} \mathrm{PO}_{4}$.

Table 2 shows that the catalyst $\left(\mathrm{Fe}_{2} \mathrm{O}_{3} / \mathrm{AC}_{(\mathrm{KOH})}\right)$ is active for liquid phase oxidation of cyclohexanol to cyclohexanone (35.8\% conversion) while the catalyst $\left(\mathrm{Fe}_{2} \mathrm{O}_{3} / \mathrm{AC}_{\left(\mathrm{H}_{3} \mathrm{PO}_{4}\right)}\right)$ is active for the dehydration of cyclohex- 
anol to cyclohexene (8.3\% conversion) and further to benzene (2.4\% conversion) by dehydration/dehydrogenation route as shown in Scheme 1.

In further studies, $\left(\mathrm{Fe}_{2} \mathrm{O}_{3} / \mathrm{AC}_{(\mathrm{KOH})}\right)$ was used as a catalyst for the liquid phase oxidation of alcohols (cyclohexanol to cyclohexanone, isopropanol to acetone, octanol to octanal, benzyl alcohol to benzaldehyde, and cinnamyl alcohol to cinnamaldehyde).

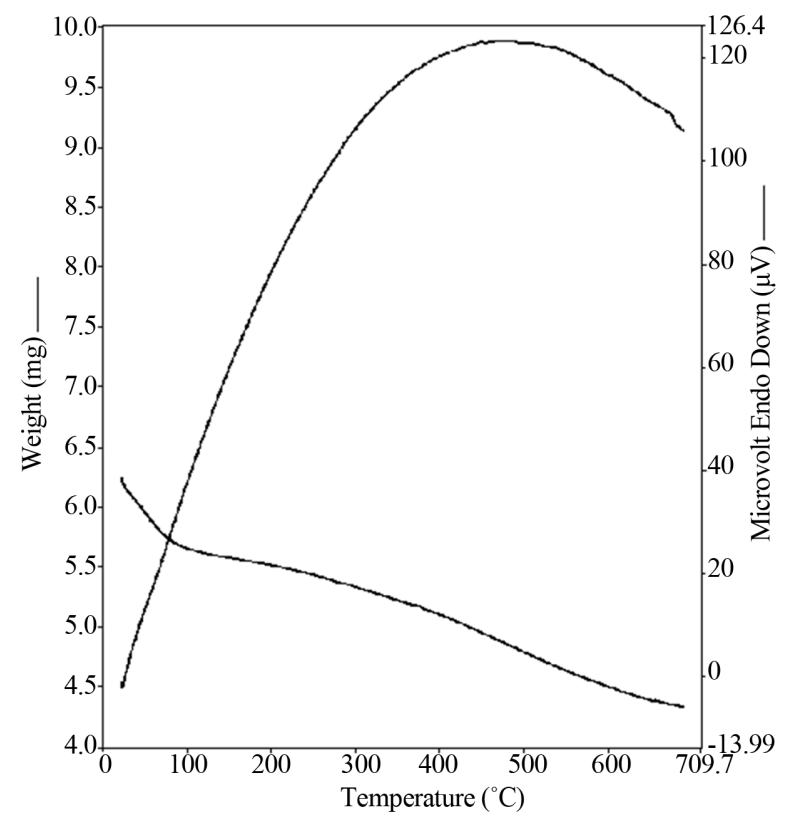

(a)

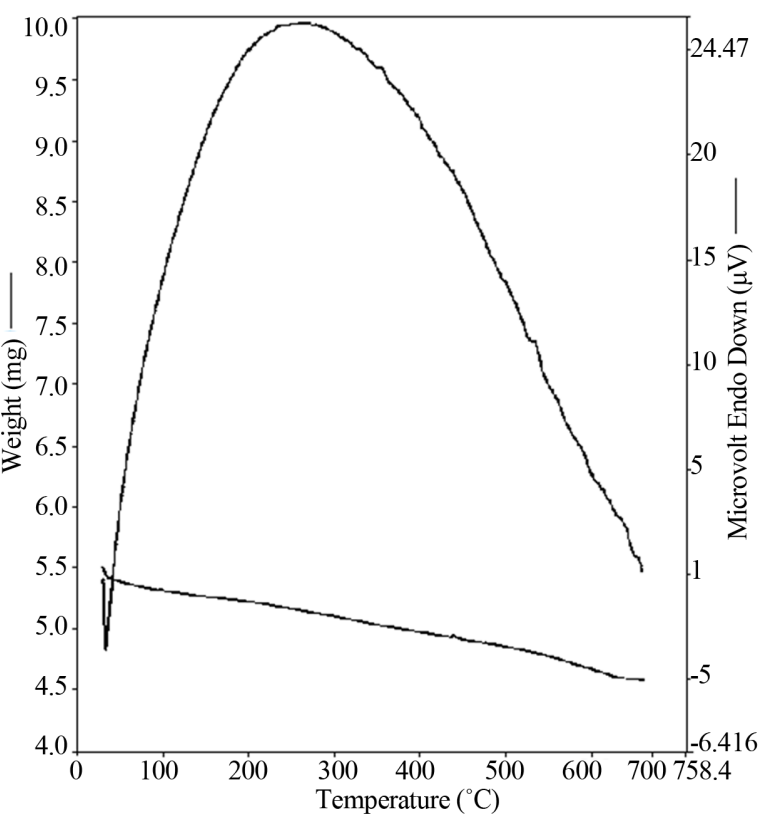

(b)

Figure 9. (a) TGA/DTA of activated carbon impregnated with KOH; (b) TGA/DTA of iron supported on activated carbon impregnated with $\mathrm{KOH}$.

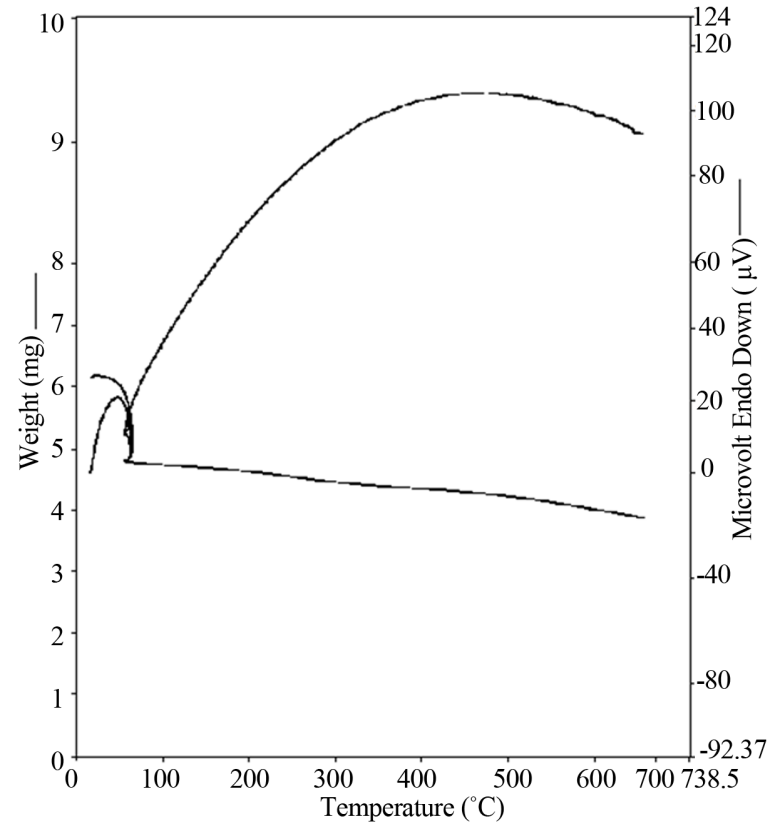

(a)

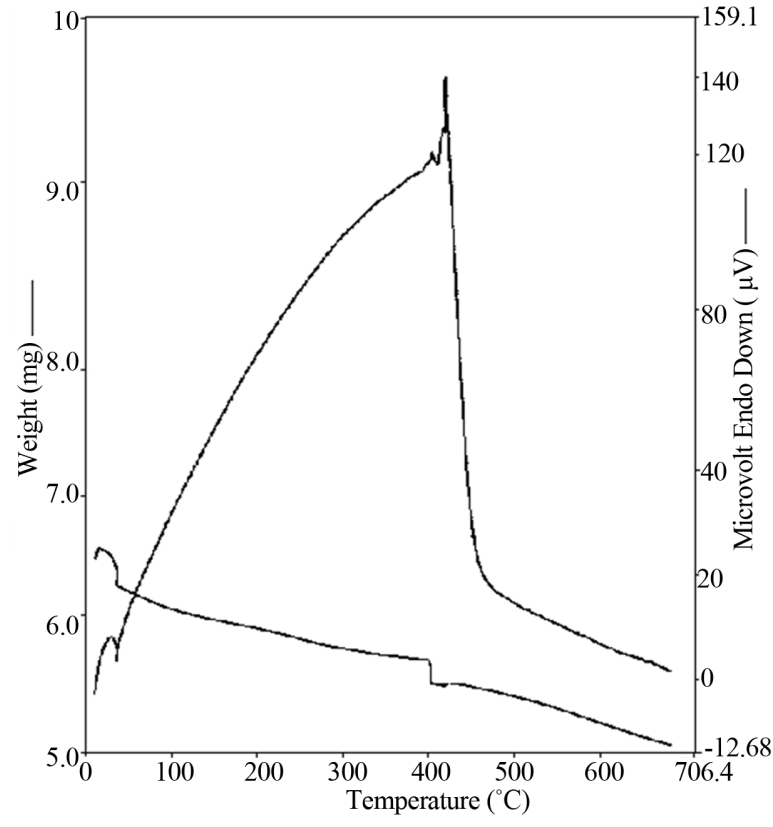

(b)

Figure 10. (a) TGA/DTA of activated carbon impregnated with $\mathrm{H}_{3} \mathrm{PO}_{4}$; (b) TGA/DTA of iron supported on activated carbon impregnated with $\mathrm{H}_{3} \mathrm{PO}_{4}$. 
Table 2. Activity profile of $\mathrm{Fe}_{2} \mathrm{O}_{3} / \mathrm{AC}_{(\mathrm{KOH})}$ and $\mathrm{Fe}_{2} \mathrm{O}_{3} / \mathrm{AC}_{\left(\mathrm{H}_{3} \mathrm{PO}_{4}\right)}$ catalysts for liquid phase oxidation of cyclohexanol at $363 \mathrm{~K}$.

\begin{tabular}{cccc}
\hline Catalyst & Reactant & Products & $\%$ Yield \\
\hline $\mathrm{Fe}_{2} \mathrm{O}_{3} / \mathrm{AC}_{(\mathrm{KOH})}$ & Cyclohexanol & Cyclohexanone & 35.8 \\
$\left.\mathrm{Fe}_{2} \mathrm{O}_{3} / \mathrm{AC}_{\left(\mathrm{H}_{3} \mathrm{PO}_{4}\right)}\right)$ & Cyclohexanol & Cyclohexene, benzene & $8.3,2.4$ \\
\hline
\end{tabular}

Reaction condition: Cyclohexanol: $10 \mathrm{~mL}$; Catalyst wt: $100 \mathrm{mg}$; Duration: 8 hours; Flow rate: $40 \mathrm{~mL} / \mathrm{min}$; Stirring: 900 rpm; analysis method; GC with FID.

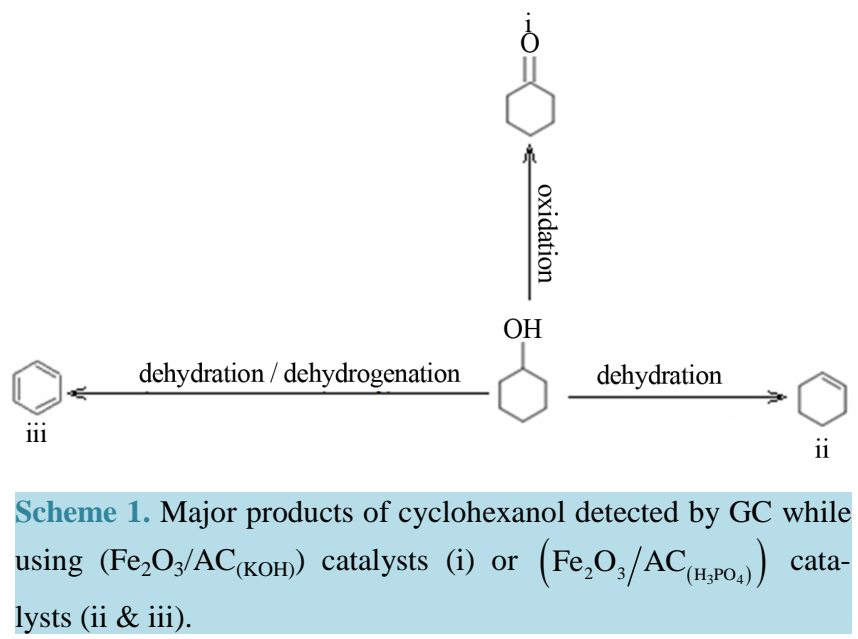

\subsection{Preliminary Studies of the Prepared Catalyst $\left(\mathrm{Fe}_{2} \mathrm{O}_{3} / \mathrm{AC}_{(\mathrm{Kо \textrm {H }})}\right)$ for the Oxidation of Cyclohexanol}

Table 3 show results obtained from the chemical analysis of reaction mixture with 2,4-dinitro phenyl hydrazine. Maximum conversion (3.8\%) was observed at $373 \mathrm{~K}$ in inert atmosphere. In the oxygenated atmosphere, a linear increase in the \% conversion of cyclohexanol to cyclohexanone was observed from $343 \mathrm{~K}$ to $373 \mathrm{~K}$ with an increase in partial pressure of oxygen from 95 to 760 Torr. This suggests that the conversion of cyclohexanol to cyclohexanone occurred through oxidation rather than dehydrogenation. At higher temperature, \% conversion increases with increase in pressure from 95 to 475 Torr, but beyond this, \% conversion decreases with an increase in the partial pressure of oxygen in Table 3.

\subsection{Time Profile Study}

Time profile studies of liquid phase oxidation of cyclohexanol to cyclohexanone over $\left(\mathrm{Fe}_{2} \mathrm{O}_{3} / \mathrm{AC}_{(\mathrm{KOH})}\right)$ were carried out to investigate the effect of reaction time on the \% conversion of cyclohexanol. This study was carried out at $343 \mathrm{~K}$ by loading $100 \mathrm{mg}$ of catalyst and $10 \mathrm{~mL}$ of reactant to a three necked batch reactor under atmospheric pressure.

Figure 11 show that 30 minutes is the induction period of the reaction duration, after which the \% conversion accelerates until 390 min. After 390 min, the \% conversion first decreases slightly and then becomes constant. This observation is in agreement with the literature [14].

\subsection{Temperature Study}

Liquid phase oxidation of cyclohexanol to cyclohexanone over $\left(\mathrm{Fe}_{2} \mathrm{O}_{3} / \mathrm{AC}_{(\mathrm{KOH})}\right)$ was carried out to study the effect of temperature on the reaction at temperature (343 - 363 K) by suspending $100 \mathrm{mg}$ of catalyst in $10 \mathrm{~mL}$ of cyclohexanol. Oxygen was passed through the reaction mixture with a flow rate of $40 \mathrm{~mL} \cdot \mathrm{min}^{-1}$ for $480 \mathrm{~min}$ under atmospheric pressure.

The results obtained (Table 4 and Figure 12) show a steady increase in the rate of reaction with rise in temperature from $343 \mathrm{~K}$ to $353 \mathrm{~K}$ as $\mathrm{pO}_{2}$ increases from 95 Torr to 760 Torr. However, at temperature $363 \mathrm{~K}$ the 
Table 3. Effect of partial pressure of oxygen and inert atmosphere on the \% conversion of cyclohexanol to cyclohexanone at temperatures (343 to $373 \mathrm{~K}$ ) measured by chemical method.

\begin{tabular}{cccccccccc}
\hline $\mathrm{pO}_{2}$ (Torr) $\rightarrow$ & 95 & 190 & 285 & 380 & 475 & 570 & 665 & 760 & $\mathrm{~N}_{2}$ 760Torr \\
\hline $\mathrm{Temp}(\mathrm{K}) \downarrow$ & & & \multicolumn{7}{c}{$\%$ Conversion } \\
\hline 343 & 3.8 & 5.8 & 8.2 & 12.6 & 15.3 & 17.7 & 20.6 & 23.5 & 1.3 \\
353 & 5.3 & 9.6 & 12.4 & 15.8 & 17.8 & 20.7 & 28.8 & 29.6 & 2.5 \\
363 & 9.3 & 15.4 & 20.7 & 27.6 & 35.6 & 29.4 & 26.5 & 19.5 & 3.2 \\
373 & 7.4 & 11.7 & 14.4 & 20.4 & 19.2 & 17.6 & 16.3 & 14.1 & 3.8 \\
\hline
\end{tabular}

Reaction conditions: Reactant: $10 \mathrm{~mL}$; Catalyst $\left(\mathrm{Fe}_{2} \mathrm{O}_{3} / \mathrm{AC}_{(\mathrm{KOH})}\right)$ : $100 \mathrm{mg}$; Duration: 8 hr; Flow: $40 \mathrm{~mL} / \mathrm{min}\left(\mathrm{O}_{2}\right.$ and/or $\mathrm{N}_{2}$ ); Stirring: $900 \mathrm{rpm}$.

\begin{tabular}{|c|c|c|c|c|c|c|c|c|}
\hline $\mathrm{pO}_{2}$ (Torr) $\rightarrow$ & 95 & 190 & 285 & 380 & 475 & 570 & 665 & 760 \\
\hline Temp (K) $\downarrow$ & \multicolumn{8}{|c|}{ Rate $\times 10^{6}\left(\right.$ mole $\left.\cdot \mathrm{g}^{-1} \cdot \mathrm{min}^{-1}\right)$} \\
\hline 343 & 7.6 & 11.6 & 16.4 & 25.2 & 30.6 & 35.4 & 41.2 & 47.0 \\
\hline 353 & 10.6 & 19.2 & 24.8 & 31.6 & 35.6 & 41.4 & 57.6 & 59.2 \\
\hline 363 & 18.6 & 30.8 & 41.4 & 55.2 & 71.2 & 58.8 & 53.0 & 39.0 \\
\hline
\end{tabular}

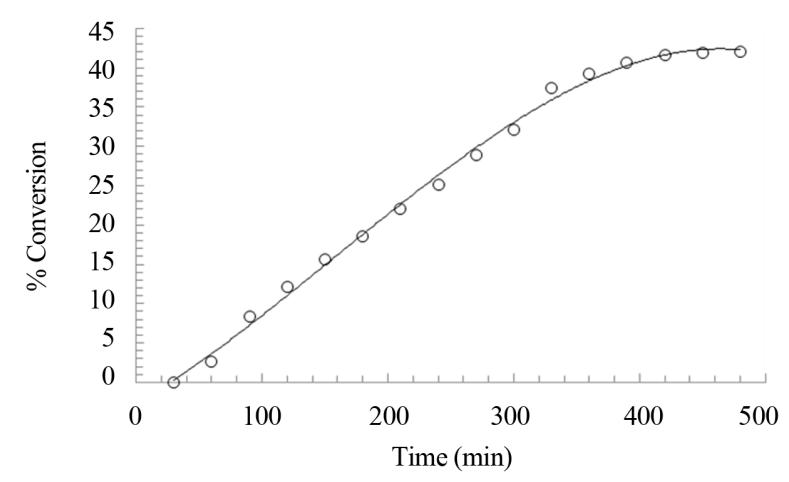

Figure 11. Time profile study of cyclohexanol oxidation to cyclohexanone, Reaction conditions: Cyclohexanol: $10 \mathrm{~mL}$; Catalyst $\left(\mathrm{Fe}_{2} \mathrm{O}_{3} / \mathrm{AC}_{(\mathrm{KOH})}\right): 100 \mathrm{mg}$; Temp: $343 \mathrm{~K}$; Flow: 40 $\mathrm{mL} / \mathrm{min}\left(\mathrm{O}_{2}\right)$; Stirring: $900 \mathrm{rpm}$.

rate of reaction only increases as the $\mathrm{pO}_{2}$ increases from 95 Torr to 475 Torr while a decline in the rate of reaction occurs as the $\mathrm{pO}_{2}$ is elevated from 475 to 760 Torr. This decrease in the \% formation of cyclohexanone is due to some side products (less than $2 \%$ ), which were detected in GC analysis. The activation energies calculated at different partial pressures (in the range 95 - 475 Torr) were $46.2 \mathrm{~kJ} / \mathrm{mole}, 50.5 \mathrm{~kJ} / \mathrm{mole}, 47.8 \mathrm{~kJ} / \mathrm{mole}$, $40.9 \mathrm{~kJ} / \mathrm{mole}, 43.4 \mathrm{~kJ} / \mathrm{mole}$, respectively. These activation energies show that the reaction is purely in the kinetic control regime.

\subsection{Effect of Partial Pressure of Oxygen}

The effect of partial pressure of oxygen on the rate of reaction, using $\left(\mathrm{Fe}_{2} \mathrm{O}_{3} / \mathrm{AC}(\mathrm{KOH})\right.$ under solvent free condition, at various partial pressures of oxygen (95 to 760 Torr), in the temperature range (343 to $373 \mathrm{~K}$ ) was studied with $100 \mathrm{mg}$ of catalyst and $10 \mathrm{~mL}$ of cyclohexanol. The flow rate of feed gases was $40 \mathrm{~mL} / \mathrm{min}$ and the reaction time was 480 minutes. Figure 13 shows that the rate of formation of cyclohexanone increases with increase in the partial pressure of oxygen from 95 to 760 Torr in the temperature range 343 - $353 \mathrm{~K}$. However, the situa- 


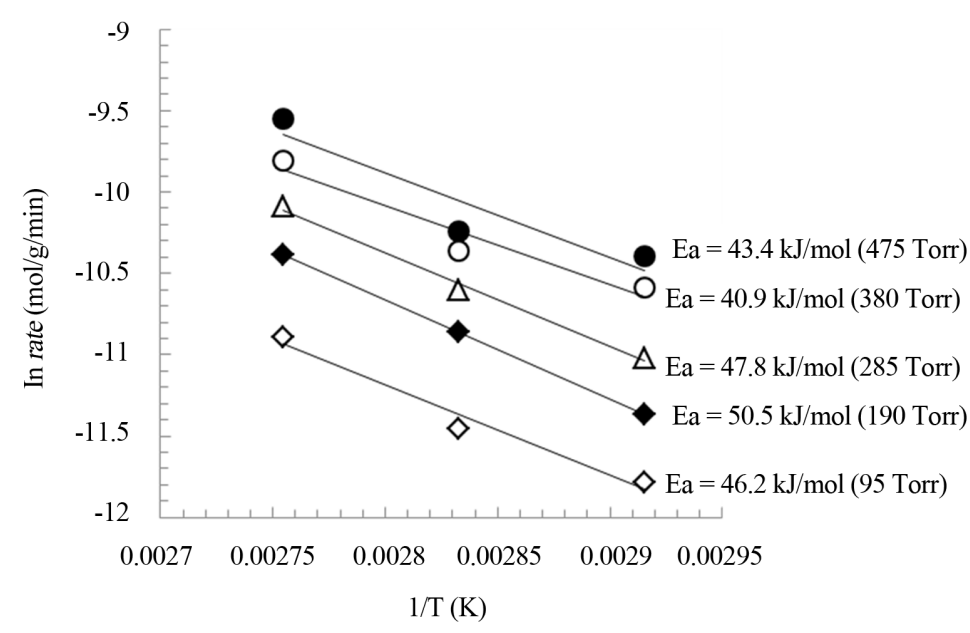

Figure 12. Arrhenius plot for the calculation of activation energies, reaction conditions: Cyclohexanol: $10 \mathrm{~mL}$; Catalyst: $100 \mathrm{mg}$; Temp: 343 - $363 \mathrm{~K}$; Flow: $40 \mathrm{~mL} / \mathrm{min}\left(\mathrm{O}_{2}\right)$; Stirring: $900 \mathrm{rpm}$; Time: $480 \mathrm{~min}$.

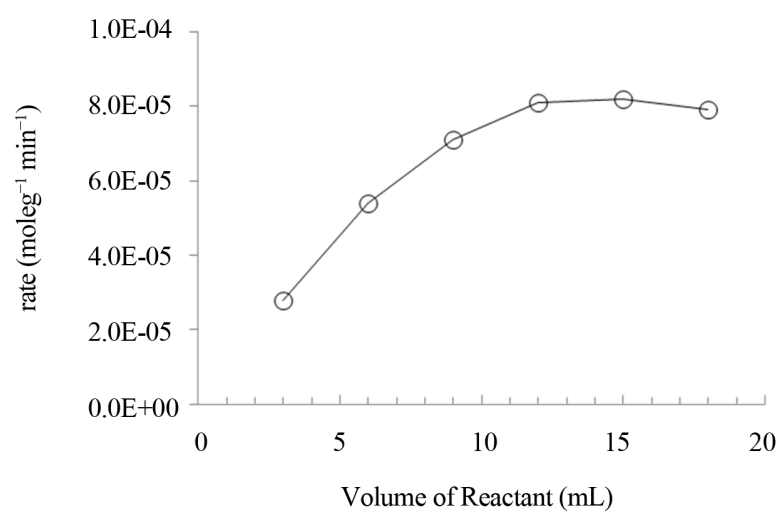

Figure 13. Effect of initial volume of reactant on the rate of reaction. Reaction conditions: Cyclohexanol: 3 - $12 \mathrm{~mL}$; Catalyst: $100 \mathrm{mg}$; Temp: $343 \mathrm{~K}$; Flow: $40 \mathrm{~mL} / \mathrm{min}\left(\mathrm{O}_{2}\right)$; Stirring: 900 rpm; Time: $480 \mathrm{~min}$.

tions at reaction temperatures of $363 \mathrm{~K}$ and $373 \mathrm{~K}$ show two different trends as partial pressure of oxygen increases from 95 to 760 Torr. A reaction temperature of $363 \mathrm{~K}$, the rate of reaction first increases with increase in the $\mathrm{pO}_{2}$ from 95 to 475 Torr until it reaches a maximum and then rapidly decreases with further increase in $\mathrm{pO}_{2}$ from 475 to 760 Torr at the same temperature. At $373 \mathrm{~K}$, the rate of reaction first increases with the increase in $\mathrm{pO}_{2}$ from 95 to 380 Torr and then decreases with the increase in $\mathrm{pO}_{2}$ from 380 to 760 torr.

This suggests that the major pathway of this reaction system is the oxidation of cyclohexanol to cyclohexanone, while dehydration and some other complicated processes are the minor path ways at higher temperature [15]-[17]. Increased rate can be attributed to the strong chemisorption of oxygen and cyclohexanol on the surface of the catalyst, while the decreased rate of formation of cyclohexanone may be due to competition for adsorption sites between oxygen and cyclohexanol.

\subsection{Effect of Initial Volume of Reactant}

Figure 14 indicates that the rate of reaction increases linearly with increase in the initial amount of cyclohexanol from 3 to $12 \mathrm{~mL}$ while after that the increase slows down and then starts decreasing with increase in the initial amount of cyclohexanol above $15 \mathrm{~mL}$. As the reaction is in solvent free condition, concentration of cyclohexanol remains constant with an increase in the initial amount of cyclohexanol. Since the rate of reaction depends 


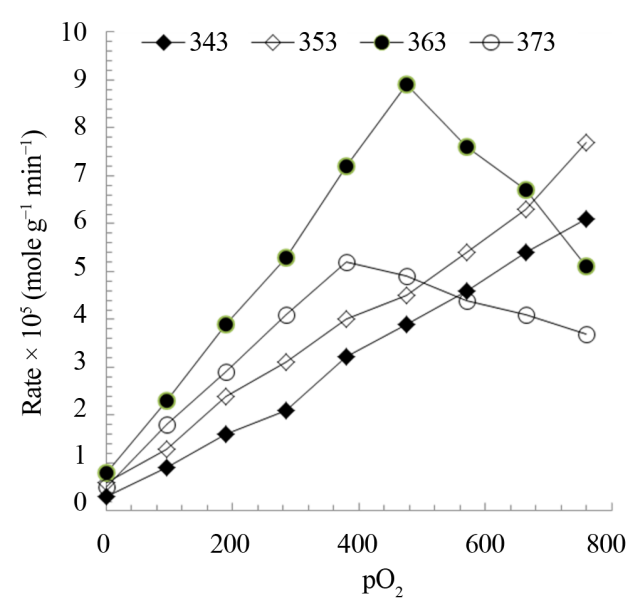

Figure 14. Effect of partial pressure of oxygen on the rate of reaction. Reaction conditions: Cyclohexanol: $10 \mathrm{~mL}$; Catalyst: $100 \mathrm{mg}$; Temp: $343 \mathrm{~K}$; Flow: $40 \mathrm{~mL} / \mathrm{min}\left(\mathrm{N}_{2} / \mathrm{O}_{2}\right)$; Partial pressure of $\mathrm{O}_{2}$ : 95 - 760 Torr; Stirring: 900 rpm; Time: 480 min.

on concentration, theoretically, there should be no increase in the rate with an increase in the amount of cyclohexanol. The probable reason for increase in the rate of formation of cyclohexanone with the increase in initial amount of cyclohexanol up to $15 \mathrm{~mL}$ is that greater number of molecules of the substrate has greater chances of chemisorption on the surface of the catalyst. This means that the particles of the catalyst are more dispersed in the increased number of molecules of the substrate and hence provide more chances to the molecules for chemisorption. However, further increase in substrate ratio (above $15 \mathrm{~mL}$ of cyclohexanol), mole formation of the product and rate of reaction achieve a steady state. This can be explained simply by asserting that as the number of molecules of the substrate increases and the number of particles of the catalyst remains the same, extra substrate molecules have no chances to adsorb within the specified reaction time (480 minutes). Another reason may be that the increase in volume of the reactant up to $15 \mathrm{~mL}$ in a reactor increases the dispersion and also increases residence time for the contact of oxygen with the catalyst particles [18].

\subsection{Effect of Catalyst Loading}

Liquid phase oxidation of cyclohexanol to cyclohexanone in solvent free conditions catalyzed by $\left(\mathrm{Fe}_{2} \mathrm{O}_{3} /\right.$ $\left.\mathrm{AC}_{(\mathrm{KOH})}\right)$ was studied with variable amounts of catalyst loading $(0.02 \mathrm{~g}$ to $0.3 \mathrm{~g})$ at $343 \mathrm{~K}$ in a constant amount $(10 \mathrm{~mL})$ of cyclohexanol under atmospheric pressure for 480 minutes. Figure 15 shows that with increase in the catalyst loading the \% conversion increases while the rate of reaction decreases. General reason for this observation may be that with increase in catalyst loading the number of catalyst molecules increases. Less amount of catalyst means small catalyst to reactant molecules ratio. This ratio increases with increase in the amount of catalyst. Thus at a large catalyst to reactant molecules ratio, more catalyst molecules are available to excite the reactant molecules, and hence \% conversion increases. However, at very large catalyst to reactant molecules ratio, the number of catalyst molecules exceeds the number of reactant molecules, and hence \% conversion slows down, and remains almost constant. Another possible reason may be that for large catalyst quantities the rate of reaction is limited by the transport of molecular oxygen to the catalyst surface [19].

\subsection{Primary and Secondary Alcohol}

Cyclohexanol and isopropanol were chosen among secondary alcohols as model substrates for liquid phase oxidation by $\left(\mathrm{Fe}_{2} \mathrm{O}_{3} / \mathrm{AC}_{(\mathrm{KOH})}\right)$ catalyst. Cyclohexanol oxidation to cyclohexanone was studied in solvent free condition and was found to give $32.1 \%$ conversion with good selectivity (98.6\%), while liquid phase oxidation of isopropanol yielded $93 \%$ with $99 \%$ selectivity in aqueous medium as shown in (Table 5). From the class of primary alcohols, octanol, benzyl alcohol and cinnamyl alcohol were selectively converted to their corresponding aldehydes. 


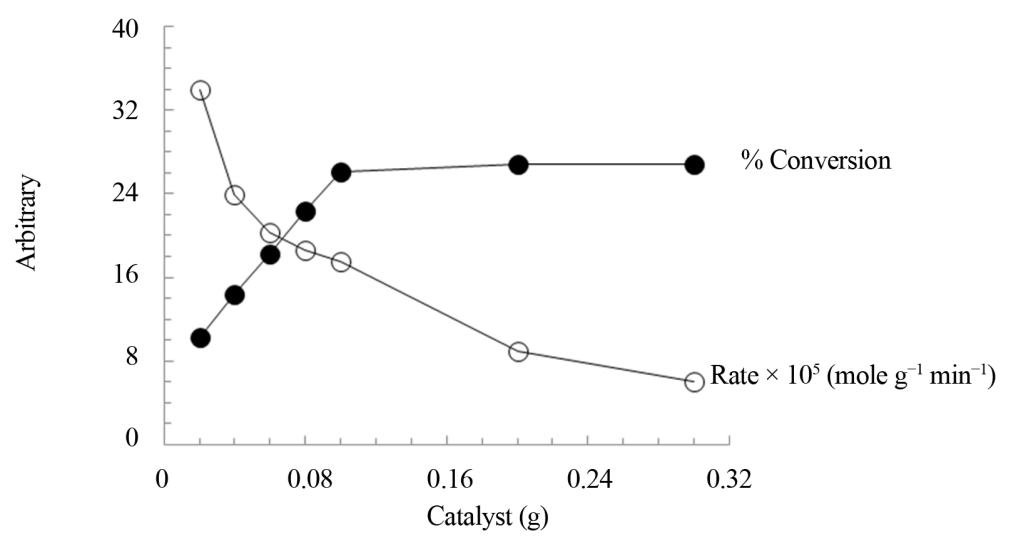

Figure 15. Effect of catalyst weight on the \% conversion of cyclohexanol and rate of reaction. Reaction conditions: Cyclohexanol: $10 \mathrm{~mL}$; Catalyst: 0.02 - 0.3 g; Temp: $343 \mathrm{~K}$; Flow: $40 \mathrm{~mL} / \mathrm{min}\left(\mathrm{O}_{2}\right)$; Stirring: $900 \mathrm{rpm}$; Time: $480 \mathrm{~min}$.

Table 5. Activity profile of $\mathrm{Fe}_{2} \mathrm{O}_{3} / \mathrm{AC}_{(\mathrm{KOH})}$ catalyst for liquid phase oxidation of selected primary and secondary alcohols in solvent free condition and/or in eco-friendly solvent.

\begin{tabular}{|c|c|c|c|c|}
\hline Reactant & Product & Conversion (\%) & Selectivity (\%) & Reaction Conditions \\
\hline cyclohexanol & cyclohexanone & 32.1 & 98.6 & $\begin{array}{l}\text { Cyclohexanol: } 10 \mathrm{~mL} ;\left(\mathrm{Fe}_{2} \mathrm{O}_{3} / \mathrm{AC}_{(\mathrm{KOH})}\right): 100 \mathrm{mg} \text {; Temp: } 353 \mathrm{~K} \text {; } \\
\text { Time: } 6 \text { hr, Flow: } 40 \mathrm{~mL} / \mathrm{min}\left(\mathrm{O}_{2}\right) \text {; Stirring: } 900 \mathrm{rpm}\end{array}$ \\
\hline isopropanol & acetone & 93 & 99 & $\begin{array}{l}\text { [Isopropanol]aq }=0.2 \mathrm{M}\left(\mathrm{Fe}_{2} \mathrm{O}_{3} / \mathrm{AC}_{(\mathrm{KOH})}\right): 100 \mathrm{mg} ; \text { Temp: } 353 \\
\text { K; Time: } 2 \text { hr; Flow: } 40 \mathrm{~mL} / \mathrm{min}\left(\mathrm{O}_{2}\right) \text {; Stirring: } 900 \mathrm{rpm}\end{array}$ \\
\hline octanol & octanal & 47.8 & 98 & $\begin{array}{c}\text { Octanol:10 mL; }\left(\mathrm{Fe}_{2} \mathrm{O}_{3} / \mathrm{AC}_{(\mathrm{KOH})}\right): 100 \mathrm{mg} \text {; Temp: } 353 \mathrm{~K} \text {; Time: } \\
6 \text { hr, Flow: } 40 \mathrm{~mL} / \mathrm{min}\left(\mathrm{O}_{2}\right) \text {; Stirring: } 900 \mathrm{rpm}\end{array}$ \\
\hline benzyl alcohol & benzaldehyde & 43.6 & 99.9 & $\begin{array}{l}\text { Benzyl alcohol: } 10 \mathrm{~mL} ;\left(\mathrm{Fe}_{2} \mathrm{O}_{3} / \mathrm{AC}_{(\mathrm{Kон})}\right): 100 \mathrm{mg} \text {; Temp: } 353 \\
\text { K; Time: } 6 \mathrm{hr} \text {, Flow: } 40 \mathrm{~mL} / \mathrm{min}\left(\mathrm{O}_{2}\right) \text {; Stirring: } 900 \mathrm{rpm}\end{array}$ \\
\hline cinnamyl alcohol & cinnamaldehyde & 89 & 92.5 & $\begin{array}{l}\text { Cinnamyl alcohol }(0.013 \mathrm{~mol}) \text { in } 20 \mathrm{~mL} \text { water; } \\
\left(\mathrm{Fe}_{2} \mathrm{O}_{3} / \mathrm{AC}_{(\mathrm{KOH})}\right): 100 \mathrm{mg} \text {; Temp: } 353 \mathrm{~K} \text {; Time: } 2 \mathrm{hrs,} \\
\text { Flow: } 40 \mathrm{~mL} / \mathrm{min}\left(\mathrm{O}_{2}\right) \text {; Stirring: } 900 \mathrm{rpm}\end{array}$ \\
\hline
\end{tabular}

Octanol converted to octanal (47.8\%) with 98\% selectivity while benzyl alcohol converted to benzaldehyde with a remarkable selectivity of $99.9 \%$ in solvent free condition. Oxidation of cinnamyl alcohol was investigated in aqueous medium, obtaining $89 \%$ cinnaldehyde with $92.5 \%$ selectivity. The catalyst was found to be stable and re-generable in both solvent free conditions and/or in aqueous medium, with excellent catalytic activity and selectivity.

\section{Conclusion}

It was found that $\mathrm{Fe}_{2} \mathrm{O}_{3} / \mathrm{AC}_{(\mathrm{KOH})}$, is an efficient selective catalyst for the conversion of primary and secondary alcohols to aldehydes/ketones in the liquid phase solvent free condition, and/or in eco-friendly solvent, under atmospheric pressure and at mild temperature ranging $343-373 \mathrm{~K}$. $\mathrm{Fe}_{2} \mathrm{O}_{3} / \mathrm{AC}_{\left(\mathrm{H}_{3} \mathrm{PO}_{4}\right)}$ was found to be active for the dehydration of cyclohexanol to cyclohexene (8.3\%), and by further dehydration/dehydrogenation to benzene (2.4\%). Catalytic activity of $\mathrm{Fe}_{2} \mathrm{O}_{3} / \mathrm{AC}_{(\mathrm{KOH})}$ in inert atmosphere, and in pure oxygenated atmosphere is in the order of $\mathrm{O}_{2} \gg \mathrm{N}_{2}$ which confirms that alcohol is converted to aldehyde/ketone through oxidation rather than through dehydrogenation. Highest activity of $\mathrm{Fe}_{2} \mathrm{O}_{3} / \mathrm{AC}_{(\mathrm{KOH})}$ was observed at $363 \mathrm{~K}$ and 475 Torr partial pressure of oxygen. Activation energies and partial pressures of oxygen show that the reaction in the temperature range 343 - $353 \mathrm{~K}$ is purely kinetically controlled, while at temperatures $363 \mathrm{~K}$ and $373 \mathrm{~K}$, it is kinetically controlled when the partial pressure of oxygen is low, and is diffusion controlled for higher partial pressure of oxygen. The catalyst exhibits a truly heterogeneous behavior and has the benefit of being recyclable by simple 
processes of filtration and drying.

\section{Acknowledgements}

The authors gratefully acknowledge financial support of Pakistan Science Foundation (Project No. PSF/Res/FUM/Chem-434) and University of Malakand (Project No. UOM/Fin/14/847).

\section{References}

[1] Puzari, A. and Baruah, J.B. (2002) Organic Oxidative Reactions Mediated by Copper. Journal of Molecular Catalysis A: Chemical, 187, 149-162. http://dx.doi.org/10.1016/S1381-1169(02)00273-X

[2] Gates, B.C. (1992) Catalytic Chemistry. John Wiley and Sons, New York.

[3] Mercera, P.D.L., Van Ommen, J.G., Doesburg, E.B.M., Burggraaf, A.J. and Ross, J.R.H. (1990) Zirconia as a Support for Catalysts: Evolution of the Texture and Structure on Calcination in Air. Applied Catalysis, 57, 127-148. http://dx.doi.org/10.1016/S0166-9834(00)80728-9

[4] Mercera, P.D.L., Van Ommen, J.G., Doesburg, E.B.M., Burggraaf, A.J. and Ross, J.R.H. (1991) Stabilized Tetragonal Zirconium Oxide as a Support for Catalysts Evolution of the Texture and Structure on Calcination in Static Air. Applied Catalysis, 78, 79-96. http://dx.doi.org/10.1016/0166-9834(91)80090-J

[5] Srinivasan, R., Taulbee, D. and Davis, B.H. (1991) The Effect of Sulfate on the Crystal Structure of Zirconia. Catalysis letters, 9, 1-7. http://dx.doi.org/10.1007/BF00769074

[6] Rafelt, J.S. and Clark, J.H. (2000) Recent Advances in the Partial Oxidation of Organic Molecules Using Heterogeneous Catalysis. Catalysis Today, 57, 33-44. http://dx.doi.org/10.1016/S0920-5861(99)00308-9

[7] Kluytmans, J.H.J., Markusse, A.P., Kuster, B.F.M., Marin, G.B. and Schouten, J.C. (2000) Engineering Aspects of the Aqueous Noble Metal Catalysed Alcohol Oxidation. Catalysis Today, 57, 143-155. http://dx.doi.org/10.1016/S0920-5861(99)00316-8

[8] Dimitratos, N., Lopez-Sanchez, J.A., Morgan, D., Carley, A.F., Tiruvalam, R., Kiely, C.J., Bethell, D. and Hutchings, G.J. (2009) Solvent-Free Oxidation of Benzyl Alcohol Using Au-Pd Catalysts Prepared by Sol Immobilisation. Physical Chemistry Chemical Physics, 11, 5142-5153. http://dx.doi.org/10.1039/b900151b

[9] Dmitry, V.B., Alexei, A.L., Stan, T.K. and Pawel, K.P. (2005) Selective Oxidation of Alcohols in a Continuous Multifunctional Reactor: Ruthenium Oxide Catalysed Oxidation of Benzyl Alcohol. Applied Catalysis A: General, 288, 175-184.

[10] Prakash, S., Charan, C., Singh, A.K. and Shahi, V.K. (2013) Mixed Metal Nanoparticles Loaded Catalytic Polymer Membrane for Solvent Free Selective Oxidation of Alcohol to Benzyldehyde in a Reactor. Applied Catalysis B: Environmental, 132-133, 62-69. http://dx.doi.org/10.1016/j.apcatb.2012.11.001

[11] Chen, Y.T., Wang, H.P., Liu, C.-J., Zeng, Z.Y., Zhang, H., Zhou, C.M., Jia, X.L. and Yang, Y.H. (2012) Formation of Monometallic Au and Pd and Bimetallic Au-Pd Nanoparticles Confined in Mesopores via Argloe-Discharge Plasma Reduction and Their Catalytic Applications in Aerobic Oxidation of Benzyl Alcohol. Journal of Catalysis, 289, 105-117. http://dx.doi.org/10.1016/j.jcat.2012.01.020

[12] Tang, Q.T., Wu, C.M., Qiao, R., Chen, Y.T. and Yang, Y.H. (2011) Catalytic Performances of Mn-Ni Mixed Hydroxide Catalysts in Liquid-Phase Benzyl Alcohol Oxidation Using Molecular Oxygen. Applied Catalysis A: General, 403, 136-141.

[13] Dina, D.J.D., Ntieche, A.R., Ndi, J.N. and Ketcha, J.M. (2012) Adsorption of Acetic Acid onto Activated Carbons Obtained from Maize Cobs by Chemical Activation with Zinc Chloride $\left(\mathrm{ZnCl}_{2}\right)$. Research Journal of Chemical Sciences, 2, 42-49.

[14] Cook, G.K. and Mayer, J.M. (1994) C-H Bond Activation by Metal Oxo Species: Oxidation of Cyclohexane by Chromyl Chloride. Journal of the American Chemical Society, 116, 1855-1867. http://dx.doi.org/10.1021/ja00084a029

[15] Basset, J.M., Vidaurre, A. and Graydon, W.F. (1972) Kinetics of Irreversible Chemisorprion: Surface Reduction of $\mathrm{MnO}_{2}$ by Cyclohexane, Cyclohexene, and 1,3- and 1,4-Cyclohexadiene. Journal of Catalysis, 26, 118-126. http://dx.doi.org/10.1016/0021-9517(72)90041-3

[16] Balsco, J., Concepcion, P., Nieto, J.M.L. andPerezpariente, J. (1995) Preparation, Characterization, and Catalytic Properties of VAPO-5 for the Oxydehydrogenation of Propane. Journal of Catalysis, 152, 1-17. http://dx.doi.org/10.1006/jcat.1995.1054

[17] Kluytmans, J.H.J., Markusse, A.P., Kuster, B.F.M., Marin, G.B. and Schouten, J.C. (2000) Engineering Aspects of the Aqueous Noble Metal Catalysed Alcohol Oxidation. Catalysis Today, 57, 143-155. http://dx.doi.org/10.1016/S0920-5861(99)00316-8

[18] Li, T., Wang, S.J., Yu, C.S., Ma, Y.C., Li, K.L. and Lin, L.W. (2011) Direct Conversion of Methane to Methanol over 
Nano-[Au/SiO $\left.{ }_{2}\right]$ in [Bmim]Cl Ionic Liquid. Applied Catalysis A: General, 398, 150-154.

http://dx.doi.org/10.1016/j.apcata.2011.03.028

[19] Nicoletti, J.W. and Whitesides, G.M. (1989) Liquid-Phase Oxidation of 2-Propanol to Acetone by Dioxygen Using Supported Platinum Catalysts. The Journal of Physical Chemistry, 93, 759-767. http://dx.doi.org/10.1021/j100339a050 